\title{
Genetic evidence for the persistence of the critically endangered Sierra Nevada red fox in California
}

\author{
John D. Perrine $\cdot$ John P. Pollinger • \\ Benjamin N. Sacks $\cdot$ Reginald H. Barrett . \\ Robert K. Wayne
}

\begin{abstract}
California is home to both the native statethreatened Sierra Nevada red fox (Vulpes vulpes necator), which historically inhabited high elevations of the Sierra Nevada and Cascade mountains, and to multiple low-elevation red fox populations thought to be of exotic origin. During the past few decades the lowland populations have dramatically expanded their distribution, and possibly moved into the historic range of the native high-elevation fox. To determine whether the native red fox persists in its historic range in California, we compared mitochondrial cytochrome- $b$ haplotypes of the only currently-known high-elevation population ( $n=9$ individuals) to samples from 3 modern lowland populations $(n=35)$ and historic (1911-1941) high-elevation $(n=22)$ and lowland $(n=7)$ populations. We found no significant population differentiation among the modern and historic
\end{abstract}

high-elevation populations (average pairwise $F_{\mathrm{ST}}=$ 0.06 ), but these populations differed substantially from all modern and historic lowland populations (average pairwise $F_{\mathrm{ST}}=0.52$ ). Among lowland populations, the historic and modern Sacramento Valley populations were not significantly differentiated from one another $\left(F_{\mathrm{ST}}=-0.06\right)$, but differed significantly from recently founded populations in the San Francisco Bay region and in southern California (average pairwise $F_{\mathrm{ST}}=$ 0.42). Analysis of molecular variance indicated that 3 population groupings (mountain, Sacramento Valley, and other lowland regions) explained $45 \%$ of molecular variance $\left(F_{\mathrm{CT}}=0.45\right)$ whereas only $4.5 \%$ of the variance was partitioned among populations within these groupings $\left(F_{\mathrm{SC}}=0.08\right)$. These findings provide strong evidence that the native Sierra Nevada red fox has persisted in northern California. However, all nine samples from this population had the same haplotype, suggesting that several historic haplotypes may have become lost. Unidentified barriers have apparently prevented gene flow from the Sacramento Valley population to other eastern or southern populations in California. Future studies involving nuclear markers are needed to assess the origin of the Sierra Nevada red fox and to quantify levels of nuclear gene flow.

\section{Introduction}

California is currently home to both native and exotic populations of red fox (Vulpes vulpes). The native 
Sierra Nevada red fox $(V . v$. necator $)$ is restricted to subalpine habitats above $1525 \mathrm{~m}(5000 \mathrm{ft})$ in the Sierra Nevada and Cascade mountain ranges of California (Grinnell et al. 1937; Schempf and White 1977). Historically the Sierra Nevada red fox existed at low densities throughout its range (Grinnell et al. 1937), but an apparently precipitous population decline led state wildlife officials to prohibit commercial trapping in 1974 and to list the subspecies as State Threatened in 1980 (Gould 1980; Lewis et al. 1999). It is currently considered "extremely endangered" and its population size, extent, and trend are unknown (CDFG 1996, 2004).

The other red fox populations in California inhabit the lowland areas $(<1066 \mathrm{~m})$ and likely consist of individuals from multiple unidentified source populations (Grinnell et al. 1937; Roest 1977; CDFG 1999; Fitzpatrick 1999; Lewis et al. 1999). Lowland foxes were first recorded in the 1880s from the plains near the Sutter Buttes in the Sacramento Valley and their origin is unknown, although some individuals may have been transported from elsewhere in North America for sport hunting or rodent control (Grinnell et al. 1937; Roest 1977; Lewis et al. 1999). Low elevation red foxes remained restricted to the Sacramento Valley through the early decades of the 20th century (Roest 1977; Lewis et al. 1999). By the 1990s, the range of the "lowland red fox" had expanded dramatically, extending throughout the Sacramento and San Joaquin Valleys to the Sierra Nevada foothills and in various coastal locations from San Francisco to San Diego (Lewis et al. 1999). However, it is unclear to what extent the new lowland populations (i.e., those outside the Sacramento Valley) arose from the original Sacramento Valley population; some of them likely derive from additional introductions from outside of California after 1950 (CDFG 1999; Fitzpatrick 1999; Lewis et al. 1999). Moreover, it is unknown whether lowland red foxes have expanded into the historic range of the native mountain red fox (Lewis et al. 1995). Morphological characteristics are insufficient to confidently conclude whether an individual red fox originated from either the native or exotic populations (Roest 1977). A genetic comparison of present-day and historic red foxes is needed to ascertain the ancestry of these populations so that appropriate management actions can be taken (Kucera 1995, 1999; Lewis et al. 1995; Aubry 1997).

Advances in DNA extraction techniques have enabled the collection of genetic data from museum specimens for use in evolutionary and population genetic studies (Pääbo 1989; Cooper 1994; Hummel 2003; Pääbo et al. 2004). Museum specimens have proven particularly valuable for comparing modern and historic levels of genetic diversity within populations that have subsequently become rare or endangered. This approach has been applied across a wide range of animal taxa and conservation questions, such as investigating bottlenecks in the greater prairie chicken (Tympanuchus cupido; Bouzat et al. 1998), northern elephant seal (Mirounga angustirostris; Weber et al. 2000), Yellowstone grizzly bear (Ursus arctos; Miller and Waits 2003), and black-footed ferret (Mustela nigripes; Wisely et al. 2002); discerning the taxonomic affiliation of the Dawson caribou (Rangifer tarandus dawsoni; Byun et al. 2002), red wolf (Canis rufus; Roy et al. 1996), and Uele River gorilla (Gorilla gorilla uellensis; Hofreiter et al. 2003); and quantifying the genetic impact of recent forest fragmentation on red squirrels (Sciurus vulgaris; Hale et al. 2001). The approach has proven particularly useful for examining temporal changes in population structure, such as in the Panamint kangaroo rat (Dipodomys panamintinus; Thomas et al. 1990), bearded vulture (Gypaetus barbatus; Gautschi et al. 2000), northeastern beach tiger beetle (Cicindela dorsalis dorsalis; Goldstein and DeSalle 2003), North Sea cod (Gadus morhua; Hutchinson et al. 2003), and adonis blue butterfly (Polyommatus bellargus; Harper et al. 2006).

Until recently, analysis of historic and recent California red foxes was hindered not by the lack of museum specimens but rather by the absence of mountain fox specimens collected after 1950 (Fig. 1). A recent ecological study of the red foxes in the Lassen Peak region of northern California (1900-3150 m elevation) enabled the collection of genetic samples for this purpose (Perrine 2005). The Lassen area was historically a main population center for the Sierra Nevada red fox (Grinnell et al. 1937; Schempf and White 1977) and is currently the only known montane red fox population in the state (Perrine 2005). However, the Lassen area may also be highly vulnerable to colonization by lowland red foxes from the Sacramento Valley $<70 \mathrm{~km}$ away, which is within the potential dispersal radius of red fox (Larivière and Pasitschniak-Arts 1996). Furthermore, escapees from several red fox fur farms in the Lassen region during the 1940s and 1950s could have become naturalized in the surrounding area (Lewis et al. 1995, 1999).

Our primary objective in this study was to test the hypothesis that the Lassen red foxes are descendants of the native mountain population rather than exotic colonists. Our secondary objectives were to quantify the diversity and distribution of mitochondrial haplotypes within California, especially those unique to the mountain or lowland populations, and to obtain 


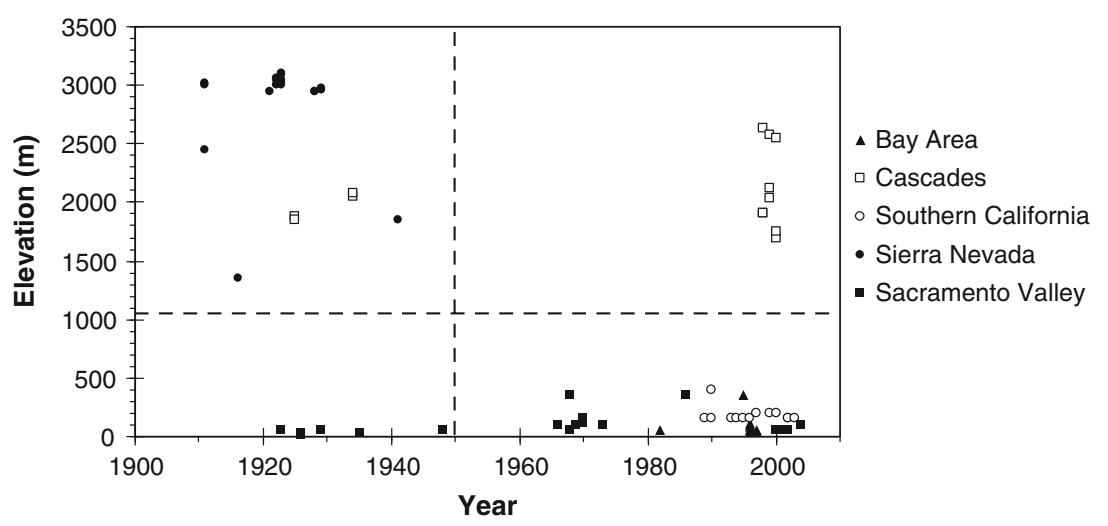

Fig. 1 Distribution of red fox specimens according to collection year and elevation. Horizontal dashed line at $1066 \mathrm{~m}$ differentiates "lowland" from "high-elevation"; vertical dashed line at 1950 differentiates "historic" from "modern." Few specimens

a preliminary assessment of population structure within the state for use in determining sampling priorities for future research. Analyses were based on a 354 base-pair region of the mitochondrial cytochrome- $b$ gene sequenced from historic and modern foxes from mountain and lowland locations throughout California.

\section{Materials and methods}

\section{Samples}

We obtained a total of 85 samples for genetic analyses, including five ear punches and nine feces collected during the Lassen Peak study (1998-2002; Perrine 2005). The nine feces, selected from a total of 227 red fox feces collected during the study, were considered likely to represent additional individuals because they were found outside the home ranges of the five collared foxes that provided the ear punches. Four of the nine fecal samples were included in our analysis after being reliably differentiated from one another and from the five captured individuals by microsatellite analysis (B. Sacks, unpublished data). Specifically, these samples were genotyped twice at 12 to $14 \mathrm{mi}$ crosatellite loci and differed by an average of 15 alleles ( $>50 \%$; range 5-19 alleles). Because allelic dropout could have influenced these comparisons, we only included individuals that were differentiated from all others at both allelic positions of at least one locus. The nine specimens from the Lassen Peak region likely represent a significant proportion of this highly localized population (Perrine 2005). Specimens from other populations were obtained from the Museum of were collected near these boundary lines, making it highly unlikely that any were misclassified. Note the lack of modern high-elevation specimens prior to 2000

Vertebrate Zoology at the University of California, Berkeley $(n=45)$, other university and municipal natural history collections in California $(n=22)$, and from several road-killed red foxes and one skeleton collected in the Sacramento Valley (see Appendix Table 4). Extractions were first attempted using untanned hide or muscle, and if these were unavailable or did not yield usable cytochrome- $b$ sequences, we used maxilloturbinal bones (Wisely et al. 2004b) as the source for DNA.

We classified specimens based upon the elevation and date of their collection (Fig. 1). Only specimens with unambiguous collection dates and localities were included in our analyses. In keeping with the operational criterion used by the California Department of Fish and Game (e.g., Lewis et al. 1993), specimens collected above $1066 \mathrm{~m}$ (3500 ft) were considered "mountain" and those below 1066 m were "lowland." Similarly, those collected prior to 1950 were considered "historic" and those collected after 1950 were considered "modern." We chose 1950 as a temporal boundary based upon a natural separation in the collection times of the available museum specimens and because the range of the lowland red fox had not expanded beyond the Sacramento Valley by this date (Lewis et al. 1999). In total, comparisons were based on 7 sample groupings (hereafter, "populations"): 3 from the mountains (Historic Cascades, Historic Sierra Nevada, Modern Cascades) and 4 from the lowlands (Historic Sacramento Valley, Modern Sacramento Valley, San Francisco Bay Area, Southern California) (Fig. 2). San Francisco Bay Area (hereafter, "Bay Area") and Southern California populations did not exist prior to 1950 and are therefore represented solely as modern populations. All specimens from the 


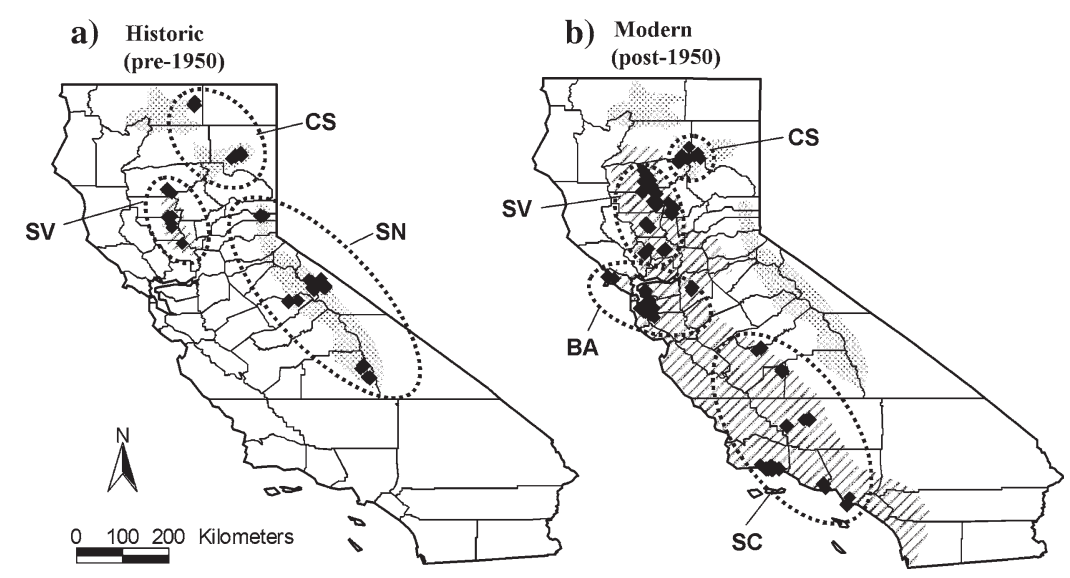

Fig. 2 Distribution of red fox specimens and 7 putative populations in California, relative to the range of the native Sierra Nevada red fox (stippling) and the lowland red fox (diagonal lines). Note the increase in the lowland red fox's range from the 1930s to the 1990s. The current distribution of the

Modern Cascades population were obtained from the Lassen Peak region. No modern specimens were available from the Sierra Nevada Mountains.

In part of its geographic range in California, the lowland red fox overlaps in distribution with a congenor, the kit fox (Vulpes macrotis; Hall 1981). However, $V$. vulpes and $V$. macrotis are unlikely to hybridize as they have dramatically different chromosome numbers $(2 n=48$ and 36 , respectively) and chromosome morphology (Wayne et al. 1987) and genetically are not closely related (Lindblad-Toh et al. 2005). Cytochrome- $b$ and other protein coding sequences differ by over $8 \%$ between the two species (Wayne et al. 1997).

\section{Laboratory procedures}

Hide and muscle samples were cut into 100-200 mg pieces, diced with a sterile blade, then soaked in sterile $1 \times$ PBS solution for $24 \mathrm{~h}$ to dilute any preservatives that may have been present. DNA was then extracted using a QIAamp minikit (Qiagen Incorporated, Valencia, CA) and the standard tissue extraction protocol $(200 \mu$ l elution volume). DNA was extracted from nasal turbinate samples using the method of Wandeler et al. (2003b) in a separate isolated and dedicated facility for low-copy DNA samples. A 100$300 \mathrm{mg}$ sample of bone fragments was chilled in liquid nitrogen in a sterile vial for $2 \mathrm{~min}$, then pulverized into a fine powder using a UV- and bleach-sterilized mortar and pestle. The powder was decalcified for $72 \mathrm{~h}$ by suspension and agitation in $1.5 \mathrm{ml}$ of $0.5 \mathrm{M}$ EDTA. Samples were then digested with $60 \mu \mathrm{l}$ of $10 \% \mathrm{~N}$-sarcosyl and $600 \mu \mathrm{g}$ of proteinase $\mathrm{K}$ for $24 \mathrm{~h}$ at $56^{\circ} \mathrm{C}$,
Sierra Nevada red fox is unknown and is therefore assumed to be the same as its historic distribution. $\mathrm{CS}=$ Cascades; $\mathrm{SN}=$ Sierra Nevada; SV = Sacramento Valley; BA = Bay Area SC = Southern California. Distributions based upon Grinnell et al. (1937) and Lewis et al. (1999)

followed by an additional $300 \mu \mathrm{g}$ of proteinase $\mathrm{K}$ and 24 additional $\mathrm{h}$ at $56^{\circ} \mathrm{C}$. Samples were then centrifuged and $1 \mathrm{ml}$ of the supernatant was transferred to a $10 \mathrm{ml}$ tube containing $5 \mathrm{ml}$ of Qiagen Buffer PB. The DNA was then bound, washed and resuspended in $50 \mu \mathrm{l}$ of TE buffer using the Qiagen Qiaquick PCR Purification Kit. A negative control was run with each set of extractions to detect possible contamination.

A 354 bp sequence of cytochrome- $b$ was isolated using primers RF14724 (5'-CAACTATAAGAACATTAATGACC-3') and RF15149 (5'-CTCAGAATGATATTTGTCCTC-3'; 441 bp PCR product), modified from L14724 and H15149, respectively (Irwin et al. 1991). Because the nasal turbinate samples were often degraded with DNA fragment lengths potentially shorter than the desired products, a set of shorter overlapping PCR products was used to generate the same DNA sequence: RF14724-RFCYTB3R and RFCYTBBF-RF15149 (RFCYTB3R: 5'-GATGCTCCGTTTGCATGTATG-3'; start position 263 of cytochrome- $b, 263$ bp PCR product, and RFCYTBBF: 5'-CTGCCGAGACGTTAACTATGGCTG-3'; start position 224 of cytochrome- $b, 218$ bp PCR product).

PCR reactions were $25 \mu \mathrm{l}$ total volume and consisted of $2 \mu \mathrm{l}$ of tissue derived DNA or $5 \mu \mathrm{l}$ of fecal or nasal turbinate derived DNA, $2.5 \mu \mathrm{l}$ of $10 \times$ PCR buffer, $2.0 \mu \mathrm{l}$ of $10 \mathrm{mM}$ dNTPs, $1.5 \mu \mathrm{l}$ of $25 \mathrm{mM}$ $\mathrm{MgCl}_{2}, 1 \mu \mathrm{l}$ each of $10 \mu \mathrm{M}$ forward and reverse primers, $0.3 \mu \mathrm{l}$ of $5 \mathrm{U} / \mu \mathrm{l}$ Taq and remainder water. PCR cycle conditions were $94^{\circ} \mathrm{C}$ for $3 \mathrm{~min}$; then 45 cycles of $94^{\circ} \mathrm{C}$ for $30 \mathrm{sec}, 50^{\circ} \mathrm{C}$ for $30 \mathrm{sec}$ and $72^{\circ} \mathrm{C}$ for $45 \mathrm{sec}$; followed by $10 \mathrm{~min}$ at $72^{\circ} \mathrm{C}$. PCR products were run on agarose gels and extracted using Ultraclean 15 DNA purification kits (Mo Bio, Solana Beach, CA) or were 
purified using multiscreen PCR micro 96 plates (Millipore Corporation, Billerica, MA). Dye terminator sequencing reactions were performed for each PCR product for each primer using Beckman DTCS reagents and products were sequenced in both directions on a Beckman CEQ2000XL capillary sequencer (Fullerton, CA) or using Applied Biosystems reagents with products sequenced on an ABI 3730 capillary sequencer (Applied Biosystems, Foster City, CA). Sequences were deposited in the EMBL/Genbank/DDBJ nucleotide database (Accession Nos. EF064207EF064220).

\section{Data analysis}

Due to the matrilineal inheritance of mtDNA, we included only one specimen per litter whenever such information was known. Within each population, haplotype and nucleotide diversity (Watterson 1975) were estimated using Arlequin 2.000 (Schneider et al. 2000). Relationships among haplotypes were described using a minimum spanning tree. To assess differentiation among population groupings, we conducted a series of hierarchical analyses of molecular variance (AMOVA; Excoffier et al. 1992) using Arlequin 2.000. These included one temporal analysis (historic vs. modern populations) and two spatial analyses: (1) mountain (Historic Sierra Nevada, Historic Cascades, Modern Cascades) versus lowland (Historic Sacramento Valley, Modern Sacramento Valley, Bay Area, Southern California); and (2) mountain, Sacramento Valley (Historic and Modern), and other lowland populations (Bay Area, Southern California). Because differentiation among mountain populations was hypothesized to be low (i.e., if originating from a single population) relative to that among lowland populations (potentially high due to multiple source populations), we also used
Arlequin to generate a matrix of pairwise $F_{\mathrm{ST}}$ estimates (Weir and Cockerham 1984) among all populations based upon haplotype frequencies. Pairwise $\Phi_{\text {ST }}$ were also estimated to incorporate pairwise differences between haplotypes (Nei and Li 1979). Significance ( $\alpha$ $=0.05$ ) was calculated using 1000 permutations and then corrected for multiple tests via the sequential Bonferroni method (Rice 1989). Haplotypes based on homologous sequences from 41 red foxes widely distributed throughout Europe (Frati et al. 1998; Genbank Accession Nos. Z80957-Z80997) were used to help elucidate nonnative ancestry among California red foxes. Although we did not necessarily expect the exotic foxes in our study to have been introduced directly from Europe, the species originated and evolved primarily in Eurasia (Kurtén 1980), making a European sample a useful reference to identify foreign haplotypes.

\section{Results}

We obtained unambiguous cytochrome- $b$ sequences from 75 of the 85 specimens $(88.2 \%)$. To be conservative, specimens yielding only partial sequences were not included in the analyses. Sequences from two specimens were excluded because they were littermates of other specimens that amplified successfully (Appendix Table 4). The 73 remaining sequences had 17 variable sites (13 transitions, 4 transversions) in $354 \mathrm{bp}$ and defined 14 haplotypes (Table 1; Fig. 3). Haplotypes differed from haplotype A by up to 6 substitutions. Three haplotypes $(\mathrm{G}, \mathrm{M}, \mathrm{N})$ shared a signature of three distinctive polymorphisms with the European haplotypes (Fig. 3), whereas the remaining haplotypes differed by one or two substitutions from haplotype A.

Table 1 Occurrence of 14 mitochondrial cytochrome- $b$ haplotypes in three historic (pre-1950) and four modern (post-1950) California red fox populations

\begin{tabular}{|c|c|c|c|c|c|c|c|c|c|c|c|c|c|c|c|}
\hline \multirow[t]{2}{*}{ Population $^{a}$} & \multirow[t]{2}{*}{$n$} & \multicolumn{14}{|c|}{ Haplotypes } \\
\hline & & $\mathrm{A}$ & $\mathrm{C}$ & $\mathrm{D}$ & $\mathrm{E}$ & $\mathrm{F}$ & $\mathrm{G}$ & $\mathrm{H}$ & $\mathrm{I}$ & $\mathrm{J}$ & $\mathrm{K}$ & $\mathrm{M}$ & $\mathrm{N}$ & $\mathrm{O}$ & $\mathrm{P}$ \\
\hline \multicolumn{16}{|l|}{ Historic } \\
\hline SN & 18 & 13 & 1 & 1 & - & - & - & - & - & 2 & - & - & - & 1 & - \\
\hline CS & 4 & 3 & 1 & - & - & - & - & - & - & - & - & - & - & - & - \\
\hline SV & 7 & 1 & - & 5 & - & - & - & - & - & - & - & - & - & - & 1 \\
\hline \multicolumn{16}{|l|}{ Modern } \\
\hline CS & 9 & 9 & - & - & - & - & - & - & - & - & - & - & - & - & - \\
\hline SV & 12 & 1 & - & 10 & - & - & 1 & - & - & - & - & - & - & - & - \\
\hline BA & 10 & - & - & - & - & 6 & 1 & 1 & - & - & - & 1 & 1 & - & - \\
\hline SC & 13 & - & - & - & 1 & 2 & 2 & - & 1 & - & 6 & - & 1 & - & - \\
\hline
\end{tabular}

a $\mathrm{SN}=$ Sierra Nevada, $\mathrm{CS}=$ Cascades, $\mathrm{SV}=$ Sacramento Valley, BA = San Francisco Bay Area, SC $=$ Southern California 


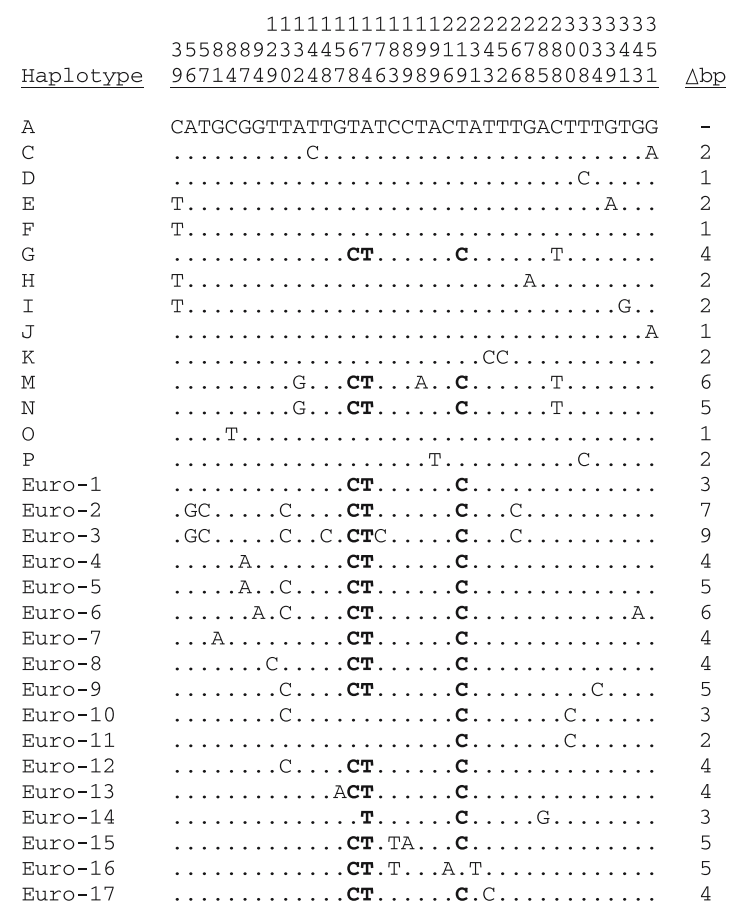

Fig. 3 Variable sites in the 354 bp region of the cytochrome- $b$ gene in red foxes from California (this study) and Europe $(n=41$; Frati et al. 1998). Note that the 17 European haplotypes shared bases in positions 168,174 or 219. California haplotypes $\mathrm{G}, \mathrm{M}$, and $\mathrm{N}$ also shared these bases, in contrast with other California haplotypes

Only haplotypes A and D (differing by one substitution) occurred in both high-elevation and lowland populations, and the remaining 12 haplotypes were exclusive to either the mountains or the lowlands (Table 1; Fig. 4). Haplotype A accounted for 25 of 31 $(80.6 \%)$ mountain specimens and two of $42(4.8 \%)$ lowland specimens (both from the Sacramento Valley). Haplotype D accounted for one of 31 (3.2\%) mountain

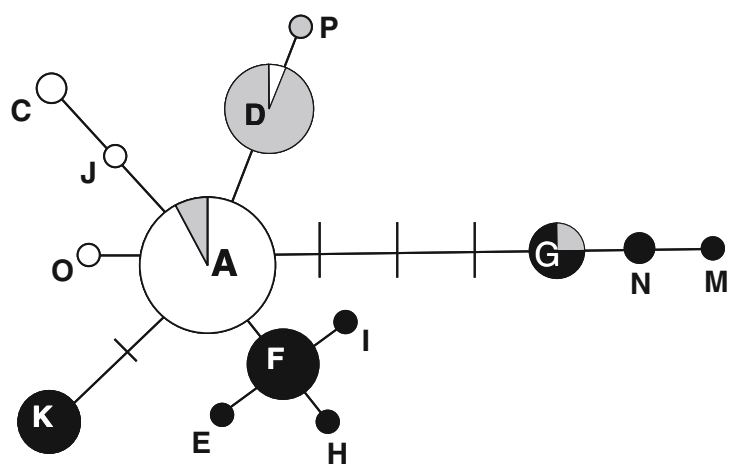

Fig. 4 Minimum spanning tree illustrating relationships among 14 cytochrome- $b$ haplotypes. Circles indicating haplotypes are shown in proportion to their frequency in the sample and colorcoded with respect to their origin in mountain (white), Sacramento Valley (gray), or other lowland (black) population. Lines indicate unsampled haplotypes specimens and 15 of $42(35.7 \%)$ lowland specimens, all from the Sacramento Valley. All three haplotypes with the European signature were restricted to lowland populations. Of the eight haplotypes that were unique to a single population, six were represented by a single individual. Haplotype $\mathrm{K}$ occurred only in the six foxes from Santa Barbara County within the Southern California population.

All nine specimens in the Modern Cascades (i.e., Lassen Peak) population had haplotype A, which was also the most common haplotype in the Historic Cascades $(75 \%)$ and Historic Sierra Nevada (72.2\%) populations. Three haplotypes occurred in the Modern Sacramento Valley population but D was the most prevalent $(83.3 \%)$. Despite the geographic proximity of the Sacramento Valley and the Bay Area, they shared only haplotype $\mathrm{G}$, which was present in one sample from each population. The Bay Area and Southern California populations shared three haplotypes and these populations had the greatest haplotype and nucleotide diversity (Table 2).

The temporal AMOVA allocated no significant proportion of the genetic variation to time period (historic vs. modern) $\left(F_{\mathrm{CT}}=-0.07 ; P=0.64\right)$. The 2group spatial AMOVA allocated $30 \%$ of the genetic variation to that between the mountain and lowland groups of populations $\left(F_{\mathrm{CT}}=0.30 ; P=0.03\right)$ and $20.9 \%$ of the variability among the populations to that within the 2 groups $\left(F_{\mathrm{SC}}=0.30 ; P<0.001\right)$. The 3 -group spatial AMOVA allocated $45 \%$ of the genetic variation to that among the mountain, Sacramento Valley, and other lowland population groupings $\left(F_{\mathrm{CT}}=0.45 ; P=\right.$ 0.01 ) and only $4.5 \%$ of the variability among populations within groups $\left(F_{\mathrm{SC}}=0.08 ; P<0.001\right)$. Thus, the 3 -group model was a considerably better fit to the data than the 2-group model. Pairwise $F_{\mathrm{ST}}$ and $\Phi_{\mathrm{ST}}$ values

Table 2 Haplotype and nucleotide diversity associated with a 354-bp sequence of the mitochondrial cytochrome- $b$ gene among seven populations

\begin{tabular}{llllll}
\hline Population $^{\mathrm{a}}$ & $n$ & $\begin{array}{l}\text { Haplotype } \\
\text { diversity }\end{array}$ & SD & $\begin{array}{l}\text { Nucleotide } \\
\text { diversity }\end{array}$ & SD \\
\hline $\begin{array}{l}\text { Historic } \\
\text { SN }\end{array}$ & 18 & 0.48 & 0.14 & 0.0018 & 0.0016 \\
CS & 4 & 0.50 & 0.27 & 0.0028 & 0.0028 \\
SV & 7 & 0.52 & 0.21 & 0.0016 & 0.0017 \\
Modern & & & & & \\
CS & 9 & 0 & 0 & 0 & 0 \\
SV & 12 & 0.32 & 0.16 & 0.0027 & 0.0022 \\
BA & 10 & 0.67 & 0.16 & 0.0087 & 0.0056 \\
SC & 13 & 0.78 & 0.10 & 0.0100 & 0.0061 \\
\hline
\end{tabular}

a $\mathrm{SN}=$ Sierra Nevada, CS = Cascades, SV = Sacramento Valley, BA = San Francisco Bay Area, SC = Southern California 
Table 3 Pairwise $F_{\mathrm{ST}}$ and $\Phi_{\mathrm{ST}}$ estimates among three historic (pre-1950) and four modern (post-1950) California red fox populations

\begin{tabular}{llllllll}
\hline & Historic SN & Historic CS & Historic SV & Modern CS & Modern SV & Modern BA & Modern SC \\
\hline Historic SN & - & -0.08 & $0.51^{*}$ & 0.00 & $0.45^{*}$ & $0.36^{*}$ & $0.27^{*}$ \\
Historic CS & -0.10 & - & 0.51 & 0.22 & $0.41^{*}$ & 0.18 & 0.11 \\
Historic SV & $0.42^{*}$ & 0.42 & - & $0.75^{*}$ & -0.06 & $0.40^{*}$ & $0.32^{*}$ \\
Modern CS & 0.06 & 0.22 & $0.73^{*}$ & - & $0.54^{*}$ & $0.31^{*}$ & 0.21 \\
Modern SV & $0.54^{*}$ & $0.60^{*}$ & -0.06 & $0.80^{*}$ & - & $0.40^{*}$ & $0.33^{*}$ \\
Modern BA & $0.44^{*}$ & $0.39^{*}$ & $0.40^{*}$ & $0.65^{*}$ & $0.51^{*}$ & - & 0.09 \\
Modern SC & $0.38^{*}$ & $0.31^{*}$ & $0.33^{*}$ & $0.56^{*}$ & $0.44^{*}$ & 0.18 & - \\
\hline
\end{tabular}

Below diagonal measures are based solely on haplotype frequencies $\left(F_{\mathrm{ST}}\right)$; above diagonal estimates incorporate pairwise differences in sequence divergence $\left(\Phi_{\mathrm{ST}}\right)$

${ }^{\text {a }} \mathrm{SN}=$ Sierra Nevada, CS = Cascades, SV = Sacramento Valley, BA = San Francisco Bay Area, SC = Southern California

* significant at $\alpha=0.05$ using sequential Bonferroni correction for multiple tests (Rice 1989)

were consistent with these analyses, indicating no significant differentiation among the historic and modern high-elevation populations, but significant and substantial genetic differentiation between these populations and the Sacramento Valley populations (Table 3). Likewise, the modern and historic Sacramento Valley populations were not significantly different from one another, but both differed significantly from the other 2 modern lowland populations.

\section{Discussion}

Our study assessed the genetic structure among mountain and lowland red fox populations in California before and after a marked range increase by the lowland populations. High phylogenetic divergence was expected between the mountain and lowland populations due to their different hypothesized evolutionary origins. The Sierra Nevada red fox, along with the Cascade and Rocky Mountain red foxes ( $V$. $v$. cascadensis and $V$. v. macroura, respectively), likely derived from a lineage isolated south of the continental ice sheets during the Wisconsonian glaciation. When the glaciers retreated this southern refugial population became isolated in the subalpine and boreal habitats of the western mountain ranges (Aubry 1983). In contrast, the modern-day low-elevation red foxes in California are widely believed to have originated from various populations throughout eastern and northern North America, which may include European lineages due to introductions in the 17th and 18th centuries (Churcher 1959; Roest 1977; Aubry 1983; Lewis et al. 1999; Kamler and Ballard 2002).

The cytochrome- $b$ gene was chosen over the more variable control region to make use of a number of previously published cytochrome- $b$ sequences for comparison (Geffen et al. 1992; Frati et al. 1998). Even with the small sample sizes available, cytochrome- $b$ provided sufficient resolution to preliminarily assess structure among California red fox populations. In fact, the diversity of haplotypes in California was comparable that observed for the Mediterranean Basin (Fig. 3; Frati et al. 1998). However, inferences based on mitochondrial DNA reflect only matrilineal history and gene flow. Juvenile male red foxes are more likely to disperse than females and usually travel two to three times as far $(20-30 \mathrm{~km}$ for males, $10-15 \mathrm{~km}$ for females), although occasional instances of both males and females dispersing $>70 \mathrm{~km}$ (the distance between Lassen Peak and the Sacramento Valley) have been documented (Phillips et al. 1972; Storm et al. 1976; Voigt 1987; Rosatte 2002). Therefore, levels of nuclear gene flow may be higher than revealed by analysis of mtDNA. With this caveat in mind, however, several important findings emerged from our study, as discussed below.

\section{Population differentiation}

Analysis of cytochrome- $b$ haplotype frequencies found no significant genetic differentiation between modern and historic populations within the range of the Sierra Nevada red fox in California. All nine of the modern Cascades specimens from Lassen Peak had the haplotype (A) that was the most abundant haplotype in the Cascades and Sierra Nevada populations in California nearly a century earlier. The prominence of this haplotype in the mountain populations and its scarcity among the lowland populations is strong evidence that a remnant of the native, state-threatened Sierra Nevada red fox persists in the Lassen Peak region. The lack of haplotype diversity within this modern population is consistent with high levels of genetic drift and loss of rare alleles as would be expected within small, isolated populations (Wright 1978), as the Lassen Peak population appears to be (Perrine 2005). We cannot, however, exclude the possibility that the Lassen Peak 
individuals were from a single family group, although the temporal and spatial breadth of the sample makes this unlikely. The low levels of haplotype and nucleotide diversity observed in all three mountain fox populations are consistent with other species thought to exist in refugial Sierra Nevada populations (e.g., Wisely et al. 2004a). The lack of genetic differentiation between California's Cascade and Sierra Nevada populations supports Grinnell et al.'s (1937) characterization of these populations as the same subspecies, as opposed to the original inclusion of the California Cascades population with the more northerly Cascade Range populations in V. v. cascadensis (Merriam 1900; Grinnell et al. 1930). Moreover, haplotype O, which occurred in one fox from the historic Sierra Nevada population and which differs from haplotype A by a single substitution, is the dominant haplotype in modern Cascade foxes from Washington (Perrine 2005), suggesting little differentiation between these two currently recognized subspecies.

In contrast to the close relationships among mountain populations, $F_{\mathrm{ST}}$ estimates between mountain and lowland populations in California exceeded 0.25 in all cases (range $=0.31-0.80$ ), indicating "very great" divergence (Wright 1978). Specifically, the Modern Cascades population was highly divergent from all lowland populations ( $F_{\mathrm{ST}}$ range: $\left.0.56-0.80\right)$. Thus, we conclude that the modern-day Lassen Peak population should be managed as the native, state-threatened Sierra Nevada red fox, in the absence of any evidence to the contrary.

Also in contrast to the mountain populations, lowland red fox populations in California did not constitute a single interbreeding population. The Sacramento Valley population, which is the original lowland population in California (Grinnell et al. 1937), was clearly distinct from the other two recently founded lowland populations (Lewis et al. 1999). This observation supports the previous suggestion (CDFG 1999) that the San Francisco Bay Area and Southern California populations were not founded by foxes dispersing from the Sacramento Valley. Three of the eight haplotypes in the Bay Area and Southern California populations $(30 \%$ and $23 \%$ of samples, respectively) shared the $3 \mathrm{bp}$ signature present in the European fox samples but absent from the historic populations in California's mountains and Sacramento Valley. The presence of this signature does not necessarily indicate an anthropogenic translocation from Europe to California in the past century, as none of the complete haplotypes matched any of the 17 European haplotypes reported by Frati et al. (1998). It is possible that these haplotypes evolved in northern or eastern North America, whose red fox populations are thought to have derived from Eurasian lineages during the Pleistocene (Aubry 1983), and were then translocated to California. Although one specimen (CSU-2589) from the modern Sacramento Valley population had the European signature, no other haplotypes were shared between the Sacramento Valley and the other lowland populations. The absence of haplotypes A and D in the San Francisco Bay Area and Southern California populations indicates that these populations were not founded by individuals dispersing from the Sacramento Valley.

Our finding that the red fox populations in the Bay Area and Southern California exhibited relatively low genetic differentiation is in agreement with a previous analysis of three California coastal red fox populations using three microsatellite loci and a $240 \mathrm{bp}$ portion of the mitochondrial control region (Fitzpatrick 1999). Low $F_{\mathrm{ST}}$ estimates may indicate high gene flow, but can also arise due to recent anthropogenic introductions from similar source populations (Fitzpatrick 1999) or high within-population genetic diversity (e.g., Whitlock and McCauley 1999). Our study and Fitzpatrick's both found substantial genetic diversity within these recently founded lowland red fox populations, which is consistent with multiple introductions from several source populations (Lewis et al. 1999).

Our evidence that the Sacramento Valley population is more similar to the native mountain red fox than to the other lowland populations in California contradicts previous ideas about this population. Grinnell et al. (1937: 385-386) found the presence of red fox in the Sacramento Valley "altogether anomalous" considering the boreal habitats favored by the native red fox, leading these authors to surmise that the population had been "planted there by man" by the late 1880s. Their hypothesis was supported by morphological evidence indicating that the Sacramento Valley foxes more closely resembled specimens from central North America ( $V . v$. regalis) than specimens from the Sierra Nevada (Roest 1977). However, the fact that the dominant haplotype in the Sacramento Valley differs by only a single substitution from that in the mountain populations, but by up to seven substitutions from haplotypes in the other low elevation populations, clearly indicates that the Sacramento Valley foxes are more closely related to the native mountain foxes than to the other lowland populations. Moreover, the occurrence of shared haplotypes between the mountain and Sacramento Valley populations suggests the possibility that the observed differences in haplotype frequencies could have arisen solely via drift over the past century. 
Threats of hybridization

It has been hypothesized that mountain red fox are specialists that became restricted to high-elevation habitats following the retreat of the glaciers at the end of the Pleistocene, and that lowland red fox are dietary and habitat generalists that could potentially disperse into these mountainous areas and threaten the persistence of mountain red fox via hybridization and resource competition (e.g., Aubry 1983; Lewis et al. 1995; Kamler and Ballard 2002). Of all the lowland populations representing such a threat to the Lassen Peak population, the Sacramento Valley region is the closest geographically, and therefore the most likely source of lowland immigration. However, the pairwise $F_{\mathrm{ST}}$ value between the Lassen region and the modern Sacramento Valley population was the largest of any in this study, indicating low or nonexistent gene flow. It is unclear what has prevented substantial immigration from the valley to the mountains, or vice versa, over the past century. Red foxes are mobile and highly adaptable generalists, and few barriers to dispersal have been identified other than major rivers and water courses (Storm et al. 1976; Voigt 1987). Yet, similar to California, an unidentified barrier exists between mid-elevation and high-elevation red fox populations in Yellowstone National Park (Swanson et al. 2005). In the Cascades of Washington, a dense belt of conifer forest separates the lowland red fox from the native mountain red fox, but the forest itself is probably not the barrier to gene flow as this habitat could easily be crossed by red foxes (Aubry 1984).

The barrier restricting mountain red foxes to high elevation habitats may also prevent lowland red foxes from dispersing into or establishing there. For example, dispersing red foxes may select habitats that are similar to their natal habitats, as has been hypothesized to account for habitat-specific population structure in coyotes (Canis latrans; Sacks et al. 2004, 2005) and gray wolves (Canis lupus; Carmichael et al. 2001; Geffen et al. 2004). Habitat-specific behavioral differences, including differences in social structure, dispersal rates and dispersal distances, likely contribute to the significant genetic structure observed among urban red fox populations and between the urban and adjacent rural populations (Robinson and Marks 2001; Simonsen et al. 2003; Wandeler et al. 2003a). Alternatively, the barrier could be extrinsic, such as the presence of coyotes or other dominant competitors between the mountain and lowland red fox populations. Coyotes can be an important source of mortality for smaller canids (Sargeant and Allen 1989; Ralls and White 1995; Palomares and Caro 1999; Farias et al. 2005). Spatial avoidance of coyotes by red foxes has led to the ele- vational stratification of the two species in regions of Alberta (Dekker 1989) and Maine (Fuller and Harrison 2006) and possibly the Lassen Peak region of California (Perrine 2005). However, coyotes and red foxes co-occur at lower elevations in California (e.g., Ralls and White 1995), and there is no direct evidence that the presence of coyotes is the primary factor separating lowland from mountain red fox populations. The available genetic evidence suggests that the barrier between mountain and lowland red fox populations has existed for more than a century, although the mechanisms that created and maintain it are unclear.

Our results underscore the need for several further investigations. Analyses employing nuclear markers are needed to quantify the extent of male-biased gene flow between the lowlands and the mountains, and to detect additional private alleles within these populations. Incorporating historic and modern specimens from the Cascade Range and Rocky Mountains could resolve longstanding questions about the shared origin of these three mountain subspecies (Aubry 1983) and indicate whether there is genetic support for the proposal that they be relegated to a single subspecies (Roest 1979). Likewise, the acquisition of additional lowland specimens from throughout California, available due to control operations to protect native species, could more fully elucidate current patterns of gene flow and genetic structure among these populations. Determining the origins of the lowland populations, especially the Sacramento Valley population, would require incorporating samples from a broader geographic area to include multiple potential source populations and utilizing higher-resolution markers such as the mitochondrial control region.

\section{Management implications}

Several western states, including California, Oregon, Washington, Utah, and Idaho, likely host both native mountain and exotic lowland red fox populations (Aubry 1984; Kamler and Ballard 2002). However, only California has separate management strategies for mountain and lowland populations, under the assumption that one is native and the other exotic (Kamler and Ballard 2002). Although the elevation boundary of $1066 \mathrm{~m}$ (3500 ft) used to delimit these populations in California is arbitrary and the true boundary likely varies with latitude, our findings indicate that this operational criterion successfully separates high-elevation from lowland populations. Unfortunately, no specimens from the Sierra Nevada have been collected since 1941. In fact, it is unclear whether any red foxes currently inhabit the Sierra Nevada. Recent surveys 
using baited camera traps and track plates failed to detect red fox anywhere in the Sierra Nevada (Zielinski et al.2005), including historic population centers such as Sequoia and Kings Canyon National Parks (Green 2006). Additional targeted surveys are necessary in these areas, preferably involving the collection of genetic samples via hair snares and the collection of feces. Collaborative efforts with state and federal agencies should be established so that any available specimens (e.g., road-kills) within the historic range of the Sierra Nevada red fox are collected for analysis.

The distribution of mountain red fox appears to be extremely limited in California and their population density and distribution appear to have declined considerably in recent decades. We found no evidence that this decline is due to competition with or displacement by the exotic red fox; however, without evidence from nuclear markers, genetic introgression cannot be ruled out. Even if hybridization has not occurred to date, the threat of future immigration from lowland red fox populations, either from the west (Lewis et al. 1995) or from the east (Kamler and Ballard 2002), should not be discounted. The distribution and range expansion of these exotic populations should be carefully monitored, not just for the benefit of the native red fox but also for numerous other native species that may be negatively impacted (Lewis et al. 1999).

Acknowledgements The following collection managers made specimens available for this study: J. Bogiatto (California State University, Chico), P. Collins (Santa Barbara Natural History Museum), C. Conroy and E. Lacey (Museum of Vertebrate Zoology), J. Dines and I. Horovitz (Natural History Museum of Los Angeles County), and T. Schweitzer (Fort Roosevelt Vertebrate Collection). Special thanks to M. Schwartz and two anonymous reviewers whose comments greatly improved the manuscript. K. Aubry, S. Beissinger, A. Bidlack, C. Epps, B. Lidicker, P. Palsbøll, J. Patton, M. Statham and S. Wisely provided additional manuscript comments and suggestions. This research was supported in part by the USDI National Park Service's Biological Resource Management Division and Lassen Volcanic National Park.

\section{Appendix}

Table 4 Red fox specimens obtained for this study $(n=85)$

\begin{tabular}{|c|c|c|c|c|c|c|}
\hline Population & California county & Sample ID & Year & $\begin{array}{l}\text { Collection } \\
\text { elevation }(\mathrm{m})\end{array}$ & Institution & PCR \\
\hline \multirow[t]{5}{*}{ Historic CS } & Lassen & MVZ-34984 & 1925 & 1850 & MVZ & $\mathrm{OK}$ \\
\hline & Lassen & MVZ-35280 & 1925 & 1850 & MVZ & $\mathrm{OK}$ \\
\hline & Siskiyou & MVZ-3296 & 1904 & 2135 & MVZ & Fail \\
\hline & Siskiyou & MVZ-68857 & 1934 & 2050 & MVZ & $\mathrm{OK}$ \\
\hline & Siskiyou & MVZ-68858 & 1934 & 2050 & MVZ & $\mathrm{OK}$ \\
\hline \multirow[t]{18}{*}{ Historic SN } & Mariposa & MVZ-23696 & 1916 & 1350 & MVZ & $\mathrm{OK}$ \\
\hline & Mono & MVZ-32800 & 1921 & 2950 & MVZ & OK \\
\hline & Mono & MVZ-32809 & 1922 & 3000 & MVZ & $\mathrm{OK}$ \\
\hline & Mono & MVZ-33381 & 1922 & 3050 & MVZ & $\mathrm{OK}$ \\
\hline & Mono & MVZ-33382 & 1922 & 3050 & MVZ & OK \\
\hline & Mono & MVZ-33472 & 1923 & 3000 & MVZ & $\mathrm{OK}$ \\
\hline & Mono & MVZ-33473 & 1923 & 3000 & MVZ & $\mathrm{OK}$ \\
\hline & Mono & MVZ-33474 & 1923 & 3050 & MVZ & OK \\
\hline & Mono & MVZ-33586 & 1923 & 3100 & MVZ & OK \\
\hline & Mono & MVZ-33587 & 1923 & 3100 & MVZ & $\mathrm{OK}$ \\
\hline & Mono & MVZ-41004 & 1928 & 2950 & MVZ & $\mathrm{OK}$ \\
\hline & Mono & MVZ-41468 & 1928 & 2950 & MVZ & $\mathrm{OK}$ \\
\hline & Mono & MVZ-44097 & 1929 & 2950 & MVZ & $\mathrm{OK}$ \\
\hline & Mono & MVZ-46663 & 1929 & 2950 & MVZ & $\mathrm{OK}$ \\
\hline & Nevada & MVZ-95401 & 1941 & 1850 & MVZ & OK \\
\hline & Tulare & MVZ-16251 & 1911 & 3000 & MVZ & $\mathrm{OK}$ \\
\hline & Tulare & MVZ-16252 & 1911 & 3000 & MVZ & $\mathrm{OK}$ \\
\hline & Tulare & MVZ-16374 & 1911 & 2450 & MVZ & $\mathrm{OK}$ \\
\hline \multirow[t]{11}{*}{ Historic SV } & Colusa & MVZ-33550 & 1923 & $<50$ & MVZ & $\mathrm{OK}$ \\
\hline & Colusa & MVZ-36492 & 1926 & $<50$ & MVZ & $\mathrm{OK}$ \\
\hline & Colusa & MVZ-36493 & 1926 & $<50$ & MVZ & Fail ${ }^{*} *$ \\
\hline & Colusa & MVZ-36494 & 1926 & $<50$ & MVZ & $\mathrm{OK}$ \\
\hline & Colusa & MVZ-36495 & 1926 & $<50$ & MVZ & $\mathrm{OK}^{* *}$ \\
\hline & Colusa & MVZ-36496 & 1926 & $<50$ & MVZ & $\mathrm{OK}^{* *}$ \\
\hline & Colusa & MVZ-36497 & 1926 & $<50$ & MVZ & $\mathrm{OK}$ \\
\hline & Colusa & MVZ-46865 & 1926 & $<50$ & MVZ & Fail $* *$ \\
\hline & Colusa & MVZ-70285 & 1935 & $<50$ & MVZ & $\mathrm{OK}$ \\
\hline & Glenn & MVZ-44095 & 1929 & $<50$ & MVZ & $\mathrm{OK}$ \\
\hline & Tehama & MVZ-115439 & 1948 & 50 & MVZ & $\mathrm{OK}$ \\
\hline
\end{tabular}


Table 4 continued

\begin{tabular}{|c|c|c|c|c|c|c|}
\hline Population & California county & Sample ID & Year & $\begin{array}{l}\text { Collection } \\
\text { elevation (m) }\end{array}$ & Institution & PCR \\
\hline \multirow[t]{10}{*}{ Modern BA } & Alameda & LF-42* & 1995 & 350 & MVZ & OK \\
\hline & Alameda & REJ-1535 & 1996 & 50 & MVZ & OK \\
\hline & Alameda & REJ-1537 & 1996 & 50 & MVZ & OK \\
\hline & Alameda & REJ-1540 & 1996 & 50 & MVZ & OK \\
\hline & Marin & MVZ-175993 & 1982 & $<50$ & MVZ & OK \\
\hline & San Joaquin & REJ-1624 & 1997 & $<50$ & MVZ & $\mathrm{OK}$ \\
\hline & San Mateo & REJ-1555 & 1996 & 100 & MVZ & OK \\
\hline & San Mateo & REJ-1573 & 1996 & 100 & MVZ & OK \\
\hline & San Mateo & REJ-1575 & 1996 & 100 & MVZ & $\mathrm{OK}$ \\
\hline & San Mateo & REJ-1588 & 1997 & 50 & MVZ & OK \\
\hline \multirow[t]{14}{*}{ Modern CS } & Tehama & F01 & 1998 & 1900 & J. Perrine & OK \\
\hline & Tehama & F02 & 2000 & 1700 & J. Perrine & $\mathrm{OK}$ \\
\hline & Shasta & F03 & 2000 & 2550 & J. Perrine & OK \\
\hline & Tehama & F05 & 2000 & 1750 & J. Perrine & OK \\
\hline & Tehama & M01 & 1998 & 1750 & J. Perrine & OK \\
\hline & Shasta & Scat 8 & 1999 & 2600 & J. Perrine & Fail \\
\hline & Tehama & Scat 12 & 1999 & 2100 & J. Perrine & OK \\
\hline & Shasta & Scat 16 & 1999 & 2550 & J. Perrine & OK \\
\hline & Tehama & Scat 17 & 1999 & 2050 & J. Perrine & $\mathrm{OK}$ \\
\hline & Shasta & Scat 21 & 1998 & 2650 & J. Perrine & OK \\
\hline & Tehama & Scat 40 & 1998 & 2100 & J. Perrine & Fail \\
\hline & Shasta & Scat 330 & 2001 & 2050 & J. Perrine & Fail \\
\hline & Shasta & Scat 333 & 2001 & 2050 & J. Perrine & Fail \\
\hline & Shasta & Scat 404 & 2001 & 2000 & J. Perrine & Fail \\
\hline \multirow[t]{14}{*}{ Modern SC } & Fesno & FRC-027 & 1997 & $<200$ & FRVC & OK \\
\hline & Kern & FRC-061 & 1999 & $<200$ & FRVC & OK \\
\hline & Kern & $\mathrm{R} 003 *$ & 2003 & $50-150$ & MVZ & OK \\
\hline & Kings & FRC-087 & 2000 & $<200$ & FRVC & OK \\
\hline & Los Angeles & LA-85700 & 1988 & $250-400$ & LA NHM & Fail \\
\hline & Los Angeles & LA-87636 & 1990 & $250-400$ & LA NHM & OK \\
\hline & Los Angeles & LA-5* & 2002 & $<150$ & LA NHM & $\mathrm{OK}$ \\
\hline & Los Angeles & LA-87624 & 1989 & $<150$ & LA NHM & $\mathrm{OK}$ \\
\hline & Santa Barbara & SB-1 $*$ & 2002 & $<150$ & SB MNH & OK \\
\hline & Santa Barbara & $\mathrm{SB}-2 *$ & 1993 & $<150$ & SB MNH & $\mathrm{OK}$ \\
\hline & Santa Barbara & SB-3 $*$ & 1990 & $<150$ & SB MNH & $\mathrm{OK}$ \\
\hline & Santa Barbara & SB-4 $*$ & 1994 & $<150$ & SB MNH & $\mathrm{OK}$ \\
\hline & Santa Barbara & SB-5 $*$ & 1995 & $<150$ & SB MNH & OK \\
\hline & Santa Barbara & SB-6 $*$ & 1996 & $<150$ & SB MNH & OK \\
\hline \multirow[t]{13}{*}{ Modern SV } & Butte & CSU-2530 & 1966 & $<100$ & CSUC & OK \\
\hline & Butte & CSU-3943 & 1970 & $<150$ & CSUC & OK \\
\hline & Butte & CSU-1 * & 1995 & $<100$ & CSUC & Fail \\
\hline & Butte & $\mathrm{X}-2$ & 2001 & $<50$ & R. Alessio & OK \\
\hline & Colusa & CSU-2588 & 1968 & $<50$ & CSUC & $\mathrm{OK}$ \\
\hline & Colusa & $\mathrm{X}-1$ & 2000 & $<50$ & J. Perrine & OK \\
\hline & Glenn & CSU-2589 & 1969 & $<100$ & CSUC & $\mathrm{OK}$ \\
\hline & Glenn & CSU-5128 & 1973 & $<100$ & CSUC & $\mathrm{OK}$ \\
\hline & Glenn & PW-1 & 2004 & 100 & P. Weliver & $\mathrm{OK}$ \\
\hline & Napa & CSU-2591 & 1968 & $<350$ & CSUC & $\mathrm{OK}$ \\
\hline & Tehama & CSU-3504 & 1970 & $<100$ & CSUC & OK \\
\hline & Tehama & $\mathrm{H}-1 *$ & 1986 & $<350$ & HSU & OK \\
\hline & Yolo & $\mathrm{W}-1$ & 2002 & 50 & J. Perrine & $\mathrm{OK}$ \\
\hline
\end{tabular}

Collection elevations rounded to the nearest $50 \mathrm{~m}$. Institution abbreviations are as follows: CSUC = California State University, Chico; FRVC $=$ Fort Roosevelt Vertebrate Collection, Hanford; HSU = Humboldt State University, Arcata; LA NMH $=$ Los Angeles County Natural History Museum; MVZ = Museum of Vertebrate Zoology, UC Berkeley; SB NHM = Santa Barbara Natural History Museum. Other names indicate specimens not from official collections, such as field study animals or roadkills. PCR indicates whether a specimen yielded a usable sequence ("OK"; $n=75$ ) or not ("fail"; $\mathrm{n}=10$; also includes scats that could not be reliably differentiated from other individuals via microsatellites)

* specimen not yet assigned an official number by the institution

** specimen excluded from analysis because the animal was a known littermate of another specimen yielding a usable sequence 


\section{References}

Aubry KB (1983) The Cascade red fox: distribution, morphology, zoogeography and ecology. University of Washington, Dissertation

Aubry KB (1984) The recent history and present distribution of the red fox in Washington. Northwest Sci 58:69-79

Aubry KB (1997) The Sierra Nevada red fox (Vulpes vulpes necator). In: Harris JE, Ogan CV (eds) Mesocarnivores of Northern California: biology, management, and survey techniques. The Wildlife Society California North Coast Chapter, Arcata California, pp 47-53

Bouzat JL, Lewin HA, Paige KN (1998) The ghost of genetic diversity past: historical DNA analysis of the greater prairie chicken. Am Natural 152:1-6

Byun SA, Koop BF, Reimchen TE (2002) Evolution of the Dawson caribou (Rangifer tarandus dawsoni). Can J Zool 80:956-960

Carmichael LE, Nagy JA, Larter NC, Strobeck C (2001) Prey specialization may influence patterns of gene flow in wolves of the Canadian Northwest. Mol Ecol 10:2787-2798

CDFG (1996) The status of rare, threatened and endangered animals and plants of California. California Department of Fish and Game, Sacramento California

CDFG (1999) Managing non-native species in California: the red fox. California Department of Fish and Game, Sacramento California

CDFG (2004) Special animals. California Department of Fish and Game, Sacramento, California

Churcher CS (1959) The specific status of the New World red fox. J Mammal 40:513-520

Cooper A (1994) DNA from museum specimens. In: Herrmann B, Hummel S (eds) Ancient DNA. Springer-Verlag, New York, pp 149-165

Dekker D (1989) Population fluctuations and spatial relationships among wolves, Canis lupus, coyotes, Canis latrans, and red foxes, Vulpes vulpes, in Jasper National Park. Alberta Can Field-Natl 103:261-264

Excoffier L, Smouse PE, Quattro JM (1992) Analysis of molecular variance inferred from metric distances among DNA haplotypes: Application to human mitochondrial DNA restriction data. Genetics 131:479-491

Farias V, Fuller TK, Wayne RK, Sauvajot RM (2005) Survival and cause-specific mortality of gray foxes (Urocyon cinereoargenteus) in southern California. J Zool Lond 266:249-254

Fitzpatrick BM (1999) Genetic founder effects and admixture in California's non-native red foxes. MA thesis Humboldt State University, Arcata California

Fuller AK, Harrison DJ (2006) Ecology of red foxes and niche relationships with coyotes on Mount Desert Island, Maine. Final contract report to Acadia National Park and US National Park Service, 41 pp

Frati F, Hartl GB, Lovari S, Delibes M, Markov G (1998) Quaternary radiation and genetic structure of the red fox Vulpes vulpes in the Mediterranean Basin, as revealed by allozymes and mitochondrial DNA. J Zool Lond 245:43-51

Gautschi B, Tenzer I, Müller JP, Schmid B (2000) Isolation and characterization of microsatellite loci in the bearded vulture (Gypaetus barbatus) and cross-amplification in three Old World vulture species. Mol Ecol 31:101-112

Geffen E, Anderson MJ, Wayne RK (2004) Climate and habitat barriers to dispersal in the highly mobile gray wolf. Mol Ecol $13: 2481-2490$
Geffen E, Mercure A, Girman DJ, Macdonald DW, Wayne RK (1992) Phylogenetic relationships of the fox-like canids: mitochondrial DNA restriction fragment, site and cytochrome b sequence analyses. J Zool Lond 228:27-39

Goldstein PZ, DeSalle R (2003) Calibrating phylogenetic species formation in a threatened insect using DNA from historical specimens. Mol Ecol 12:1993-1998

Gould GI (1980) Status of the red fox in California. California Department of Fish and Game, Sacramento California

Green R (2006) Distribution and habitat associations of forest carnivores and an evaluation of the California Wildlife Habitat Relationships model for American marten in Sequoia and Kings Canyon National Parks. MS Thesis, Humboldt State University, Arcata California

Grinnell J, Dixon J, Linsdale J (1930) Vertebrate natural history of a section of northern California through the Lassen Peak region. University of California Press, Berkeley California

Grinnell J, Dixon J, Linsdale J (1937) Fur-bearing mammals of California. University of California Press, Berkeley California

Hale ML, Lurz PWW, Shirley MDF, Rushton S, Fuller RM, Wolff K (2001) Impact of landscape management on the genetic structure of red squirrel populations. Science 293:2246-2248

Hall ER (1981) The mammals of North America. John Wiley \& Sons, New York New York

Harper GL, MacLean N, Goulson D (2006) Analysis of museum specimens suggests extreme genetic drift in the adonis blue butterfly (Polyommatus bellargus). Biol J Linn Soc 88:447452

Hofreiter M, Siedel H, Van Neer W, Vigilant L (2003) Mitochondrial DNA sequence from an enigmatic gorilla population (Gorilla gorilla uellensis). Am J Phys Anthro 121:361-368

Hummel S (2003) Ancient DNA typing: methods, strategies and applications. Springer, New York

Hutchinson WF, van Oosterhout C, Rogers SI, Carvalho GR (2003) Temporal analysis of archived samples indicates marked genetic changes in declining North Sea cod (Gadus morhua). Proc R Soc Lond B 270:2125-2132

Irwin DM, Kocher TD, Wilson AC (1991) Evolution of the cytochrome b gene of mammals. J Mol Evol 32:128-144

Kamler JF, Ballard WB (2002) A review of native and nonnative red foxes in North America. Wildl Soc Bull 30:370-379

Kucera TE (1995) Recent photograph of a Sierra Nevada red fox. Cal Fish Game 81:43-44

Kucera TE (1999) Sierra Nevada red fox survey: final report CDFG Contract FG6160WM. University of California, Berkeley California

Kurtén B (1980) Pleistocene mammals of North America. Columbia University Press, New York

Larivière S, Pasitschniak-Arts M (1996) Vulpes vulpes. Mamm Species 537:1-11

Lewis JC, Golightly RT Jr, Jurek, RM (1995) Introduction of non-native red foxes in California: Implications for the Sierra Nevada red fox. Trans West Sec Wildl Soc 31:29-32

Lewis JC, Sallee KL, Golightly RT (1993) Introduced red fox in California. Nongame Bird and Mammal Report 93-10. California Department of Fish and Game, Sacramento California

Lewis JC, Sallee KL, Golightly RT (1999). Introduction and range expansion of nonnative red foxes (Vulpes vulpes) in California. Am Midl Nat 142:372-381 
Lindblad-Toh K, Wade CM, Mikkelsen TS, Karlsson EK, Jaffe DB, Kamal M, Clamp M, Chang JL, Kulbokas EJ et al. (2005) Genotype sequence, comparative analysis and haplotype structure of the domestic dog. Nature 438:803-819

Merriam CH (1900) Preliminary revision of the North American red foxes. Proc Wash Acad Sci 2:661-676

Miller CR, Waits LP (2003) The history of effective population size and genetic diversity in the Yellowstone grizzly (Ursus arctos): implications for conservation. Proc Nat Acad Sci USA 100:4334-4339

Nei M, Li WH (1979) Mathematical model for studying genetic variation in terms of restriction endonucleases. Proc Natl Acad Sci USA 76:5269-5273

Pääbo S (1989) Ancient DNA: extraction, characterization, molecular cloning, and enzymatic amplification. Proc Natl Acad Sci USA 86:1939-1943

Pääbo S, Poinar H, Serre D, Jaenicke-Després V, Hebler J, Rohland N, Kuch M, Krause J, Vigilant L, Hofreiter M (2004) Genetic analysis from ancient DNA. Ann Rev Gen 38:645-679

Palomares F, Caro TM (1999) Interspecific killing among mammalian carnivores. Am Natl 153:492-508

Perrine JD (2005) Ecology of red fox (Vulpes vulpes) in the Lassen Peak region of California, USA. PhD dissertation. University of California, Berkeley

Phillips RL, Andews RD, Storm GL, Bishop RA (1972) Dispersal and mortality of red foxes. J Wildl Mgmt 36:237-248

Ralls K, White PJ (1995) Predation on endangered San Joaquin kit foxes by larger canids. J Mammal 76:732-729

Rice WR (1989) Analyzing tables of statistical tests. Ecology 43:223-225

Robinson NA, Marks CA (2001) Genetic structure and dispersal of red foxes (Vulpes vulpes) in urban Melbourne. Aust J Zool 49:589-560

Roest AI (1977) Taxonomic status of the red fox in California. Final Report, Job II-1.3. California Polytechnic State University, San Luis Obispo, California

Roest AI (1979) Subspecies of North American red foxes (Vulpes vulpes). Unpublished presentation to the 59th Annual Meeting of the American Society of Mammalogists, Oregon State University, Corvallis, Oregon

Rosatte RC (2002) Long distance movement by a coyote, Canis latrans, and red fox, Vulpes vulpes, in Ontario: implications for disease-spread. Can Field-Natl 116:129-131

Roy MS, Geffen E, Smith D, Wayne RK (1996) Molecular genetics of pre-1940 red wolves. Conserv Biol 10:1413-1424

Sacks BN, Brown SK, Ernest HB (2004) Population structure of California coyotes corresponds to habitat-specific breaks and illuminates species history. Mol Ecol 13:1265-1275

Sacks BN, Mitchell BR, Williams CL, Ernest HB (2005) Coyote movements and social structure along a cryptic population genetic subdivision. Mol Ecol 14:1241-1249

Sargeant AB, Allen SH (1989) Observed interactions between coyotes and red foxes. J Mammal 70:631-633

Schempf PF, White M (1977) Status of six furbearer populations in the mountains of northern California. United States Forest Service, California

Schneider S, Roessli D, Excoffier L (2000) Arlequin ver 2000: a software for population genetics data analysis Genetics and Biometry Laboratory. University of Geneva, Switzerland
Simonsen V, Pertoldi C, Madsen AB, Loeschcke V (2003) Genetic differentiation of foxes (Vulpes vulpes) analysed by means of craniometry and isozymes. $\mathbf{J}$ Nat Conserv 11:109-116

Storm GL, Andrews RD, Phillips RL, Bishop RA, Siniff DB, Tester JR (1976) Morphology, reproduction, dispersal, and mortality of midwestern red fox populations. Wildl Monogr 49:1-82

Swanson BJ, Fuhrmann RT, Crabtree RL (2005) Elevational isolation of red fox populations in the Greater Yellowstone Ecosystem. Conserv Genet 6:123-131

Thomas WK, Pääbo S, Villablanca FX, Wilson AC (1990) Spatial and temporal continuity of kangaroo rat populations shown by sequencing mitochondrial DNA from museum specimens. J Mol Evol 31:101-112

Voigt DR (1987) Red fox. In: Novak M, Baker JA, Obbard ME, Malloch B (eds) Wild Furbearer management and conservation in North America. Ontario Ministry of Natural Resources, Ontario Canada, pp 379-392

Wandeler P, Funk SM, Largiadér CR, Gloors S, Breitenmoser U (2003a) The city-fox phenomenon: genetic consequences of a recent colonization of urban habitat. Mol Ecol 12:647-656

Wandeler P, Smith S, Morin PA, Pettifor RA, Funk SM (2003b) Patterns of nuclear DNA degeneration over time: A case study in historic teeth samples. Mol Ecol 12:1087-1093

Watterson G (1975) On the number of segregating sites in genetical models without recombination. Theor. Pop. Biol 7:256-276

Wayne RK, Geffen E, Girman DJ, Koepfli KP, Lau LM, Marshall CR (1997) Molecular systematics of the Canidae. Syst Biol 46:622-653

Wayne RK, Nash WG, O'Brien SJ (1987) Chromosomal evolution of the Canidae II: divergence from the primitive carnivore karyotype. Cytog Cell Genet 44:134-141

Weber DS, Stewart BS, Garza JC, Lehman N (2000) An empirical genetic assessment of the severity of the northern elephant seal population bottleneck. Curr Bio 10:1287-1290

Weir BS, Cockerham CC (1984) Estimating F-statistics for the analysis of population structure. Evolution 38:1358-1370

Whitlock MC, McCauley DE (1999) Indirect measures of gene flow and migration: $F_{\mathrm{ST}} \neq 1 /(4 \mathrm{Nm}+1)$. Heredity $82: 117-225$

Wisely SM, Buskirk SW, Fleming MA, McDonald DB, Ostrander EA (2002) Genetic diversity and fitness in black-footed ferrets before and during a bottleneck. J Hered 93:231-237

Wisely SM, Buskirk SW, Russell GA, Aubry KB, Zielinski WJ (2004a) Genetic diversity and structure of the fisher (Martes pennanti) in a peninsular and peripheral metapopulation. $\mathbf{J}$ Mammal 85:640-648

Wisely SM, Maldonado JE, Fleischer RC (2004b) A technique for sampling ancient DNA that minimizes damage to museum specimens. Conserv Genet 5:105-107

Wright S (1978) Evolution and the genetics of populations, vol 4, variability within and among natural populations. University of Chicago Press, Chicago, Illinois

Zielinski WJ, Truex RL, Schlexer FV, Campbell LA, Carroll C (2005) Historical and contemporary distributions of carnivores in forests of the Sierra Nevada, California, USA. J Biogeogr 32:1385-1407 